\title{
Exploring Environmental Issues: Places We Live
}

\author{
Sarah Haines ${ }^{1 *}$ and Ronald Hermann ${ }^{2}$ \\ ${ }^{1}$ Department of Biological Sciences, Towson University, USA; ${ }^{2}$ Department of Physics, Astronomy, and Geosci- \\ ences, Towson University, USA
}

Received: February 25, 2011 / Accepted: April 28, 2011

\begin{abstract}
The Project Learning Tree curriculum Exploring Environmental Issues: Places We Live was evaluated using a quasi-experimental research design that consisted of pre/post intervention assessments measuring differences in self-assessed content knowledge, researcher assessed content knowledge, and attitudes. Treatment groups consisted of two randomly assigned groups, one group completed 3-lessons and the other group completed 6-lessons. Analysis indicated the 6-lesson treatment group demonstrated significant gains in all three categories, while the 3-lesson group exhibited significant gains in self-assessed content knowledge. The results suggest that the curriculum is valuable in delivering placebased educational content.
\end{abstract}

Key Words: Environmental education, place-based education, environmental issues, environmental attitudes

"Corresponding Author: shaines@towson.edu

\section{Introduction}

Over the past few decades a convergence of events culminated in the need for environmental education to be more prominently undertaken within American public schools. The fact that the human population is growing exponentially, the result of which has placed a burden on both renewable and nonrenewable resources, the growing evidence that human activity may have played a major role in global climate change, and societal consumer habits linked to a "throw away society" have escalated the need for greater compulsory environmental education in K-1 2 schools. One result of such initiatives has been the increased development of curricular materials designed to provide the classroom teacher with activities to enhance students' understanding and stewardship of the environment. Inundated by such a large number of curricular materials to select from, teachers may be overwhelmed by the selection and unsure of the extent to which the materials will effectively increase student understanding of the environment and environmental issues. The present study describes the evaluation of an environmental education curriculum that seeks to increase understanding and stewardship for the environment via a series of place-based activities. The curriculum is published by Project Learning Tree, an award-winning environmental education program designed for teachers and other educators, parents, and community leaders working with youth from preschool through grade 12. Project Learning Tree curricula are international, and the environmen- 
tal concepts and issues investigated by students using the curricula apply to many regions around the globe. For example, educators in Canada, the U.S. Territories, Japan, Mexico, Sweden, Slovakia, China, Finland, Brazil, Jordan, and the Philippines use Project Learning Tree. Materials have been translated and adapted for use in these countries.

\section{Place-Based Education}

Characterized by exploration of the local community and its surroundings, and hands-on experiences of environmental discovery and problem solving, place-based education uses the environment as an integrating context (EIC) across disciplines (Lieberman \& Hoody, 1998). Although the term "place-based education" is relatively new and has only recently appeared in the educational research literature, the idea of such an instructional strategy has been written about for quite some time. We can trace the concept back to John Dewey. In his book The School \& Society, he advocates learning in the environment. "Experience [outside the school] has its geographical aspect, its artistic and its literary, its scientific and its historical sides. All studies arise from aspects of the one earth and the one life lived upon it" (1915, p. 91). A review of the literature reveals that place-based education has also been referred to by other terms. For example, Theobald and Curtiss (2000) refer to the concept of community oriented schooling. Smith \& Williams (1999) write of the concept of ecological education. The seven principles they outline include "grounding learning in a sense of place through investigation of surrounding natural and human communities(p. 6)" and "practical experiences outdoors through the application of an ethic of care (p. 6)." Traina and DarleyHill (1995) refer to bioregional education wherein place-based education extends beyond the local community and students are encouraged to consider how their actions affect the resources and ecosystems found within their bioregions. Orr (1994) argues that place-based education is critical to the future health of our planet. "The world does not need more rootless symbolic analysts," says Orr. "It needs instead hundreds of thousands of young people equipped with the vision, moral stamina, and intellectual depth necessary to rebuild neighborhoods, towns, and communities around the planet. The kind of education presently available will not help them much (p. 57)." They will need to be students of their places and competent to become, in Wes Jackson's words, "native to their places (p. 83)." Thomashow (1995) takes an interesting approach in which classroom instruction and curricular materials are centered around four thematic questions: (1) What do I know about the place where I live? (2) Where do things come from? (3) How do I connect to the earth? (4) What is my purpose as a human being? By investigating these questions through place-based instructional activities, students develop a better sense of stewardship and appreciation for their local surroundings.

\section{Essential Characteristics of Place-based Education}

According to Woodhouse \& Knapp (2000), the following are common elements of place-based education that recur through- out the body of literature currently published on the subject:

- It emerges from the particular attributes of a place. The content is specific to the geography, ecology, sociology, politics, and other dynamics of that place. This fundamental characteristic establishes the foundation of the concept.

- It is inherently multidisciplinary.

- It is inherently experiential. In many programs this includes a participatory action or service learning component; in fact, some advocates insist that action must be a component if ecological and cultural sustainability are to result.

- It is reflective of an educational philosophy that is broader than "learn to earn." Economics of place can be an area of study as a curriculum explores local industry and sustainability.

- It connects place with self and community. Because of the ecological lens through which place-based curricula are envisioned, these connections are pervasive. These curricula include multigenerational and multicultural dimensions as they interface with community resources.

Research shows that using this approach results in many benefits to students, such as enhanced critical thinking skills (Ernst \& Monroe, 2004), greater motivation to achieve in the classroom (Athman \& Monroe, 2004), reduced classroom disruption and disciplinary problems (NEETF 2000; SEER 2000; Lieberman \& Hoody, 1998; Falco, 2004), and a greater sense of responsibility and stewardship towards the environment (Bartosh, 2003). Duffin et al. (2004) report that exposure to EIC programs leads to a greater attachment to place, more time spent outside, increased civic engagement, and environmental stewardship.

Perhaps the most important goal of place-based education is to improve the environment, and to give students the skills to participate in environmental decision making in their communities. Ultimately, we want to create students who will work towards environmental action. Do school-based and informal education programs that focus on placed-based education and environmental issues, such as the program that is the topic of this study, lead to an improvement in these issues? According to Duffin et. al, (2008), they can. In their study of air quality education programs, the authors found that $46 \%$ of the programs studied reported evidence of improvements in understanding of air quality. Almost all of the programs included an action component (similar to the action component included in the curriculum being evaluated here), and programs reporting more place-based learning practices also showed more evidence of air quality improvement. Place-based inquiry can be a powerful teaching and learning tool that encourages the development of deeper content knowledge and understanding of environmental issues, which can in turn lead to personal changes in behavior that are more environmentally responsible. Many other researchers have found results similar to those described above by Duffin et.al, including Bodzin (2008), Frazier et. al. (2008), Martin (2003), and Sarkar \& Frazier (2008). Additonally, David Sobel (2004) addresses several successful programs following the place-based education model. Like many of these programs, Exploring Environmental Issues in Places We Live is based on the Belgrade Charter (UNESCO-UNEP 1976) and has 
its roots in the work of John Dewey (1959). Since the curriculum is place-based, it is appropriate for use anywhere on the globe, as students are engaged in investigations that take place in their local communities.

\section{Exploring Environmental Issues in Places We Live}

In 2006, Project Learning Tree, a division of the American Forest Foundation, launched a new secondary curriculum module, Exploring Environmental Issues in Places We Live. The purpose of this curriculum is to provide opportunities for community investigations that focus on environmental, social, and economic issues, and help students and other community members develop and strengthen their sense of place. Like many other curricula, all Project Learning Tree educational materials undergo independent and rigorous evaluations. These measures are meant to ensure that materials are balanced, effective and useful to educators. Ultimately, final versions are formally tested in dozens of classrooms by independent research teams.

In the 1990s, more than 100 professionals participated in a formative evaluation by pilot testing Project Learning Tree's PreK-8 curriculum in classrooms around the country. This was followed by a summative evaluation, conducted by the Research Commission of the North American Association for Environmental Education. The evaluation consisted of both traditional pre-test/ intervention/post-test procedures and alternative assessment techniques. The evaluation confirmed increased knowledge and positive attitudinal growths among students exposed to the curriculum. For more information, please see Project Learning Tree's Executive Summary of the 1994 National Field Study Final Report (www.plt.org).

The secondary curricula have also undergone similar formal evaluations. This study was modeled after that of Covitt et. al. (2005), which analyzed the effectiveness of the Project Learning Tree curriculum, entitled Focus on Risk. However, since these evaluations were undertaken (mostly in the 1990s), many educational practices have changed. For example, national standards in science, mathematics, social studies, and language arts have been established and put into widespread use in many countries. Likewise, many U.S. states have implemented new state standards as well. We also know more about environmental education research and place-based educational research, and how these can affect student achievement, attitudes, and bring about changes in behavior.

Additionally, student characteristics have changed over the past decade. The Millennial student, born between 1982 and 2002, has characteristics which center on 1) using technology, 2) doing things that matter, 3) working with each other, 4) being online/connected, and 5) doing it all in their timeframe (Gravett \& Throckmorton, 2007). Similarly, Net Gen (Net Generation) students are multitaskers who tend to work in groups, have grown up with computers and video games, and they tend to be self-learners who figure out solutions without consulting manuals. They tend to not be interested in text-based information or doing work in a traditional linear, logical pathway (Lippincott, 2005). Since the Places We Live curriculum is text-based, linear in many respects and requires a logical thought progression, the need for an evaluation of the extent to which the curriculum is effective with the current generation of students is well deserved. The data generated through these evaluative studies support the assumption that the model followed by the Project Learning Tree curricula is effective, but we still must re-evaluate the model periodically, especially when we are applying assumptions to a new curriculum. Otherwise, we are not being responsible researchers, as new educational standards, new research findings in the field, and the simple passage of time may cause our assumptions to become incorrect.

\section{Description of the Curriculum}

The Places We Live curriculum is composed of eight lessons that emphasize place-based educational concepts. Lessons need not be completed as a set; each lesson can act as a "stand alone" lesson. In fact, there is anecdotal evidence to suggest that many teachers are likely to select only a few of the lessons found in the module. To that end, one salient aspect of this study is the comparison of a control group to a group that completed 3 -lessons and another group that completed six activities. To provide a sense of the flow of lessons and the content covered in each, a brief description of each lesson follows.

In lesson one, Personal Places, students investigate and report on their connection with a special place and with their greater community. In the second lesson, Community Character, students explore community character and investigate the ways that communities, including their own, are responding to growth and development pressures. Lesson three, Mapping Your Community Through Time, asks student teams investigate the social, cultural, economic, aesthetic, and environmental components of their community to create map overlays and reports describing the development of their community through time. The fourth lesson, Neighborhood Design, has students explore the current design of their neighborhood, critically evaluate a variety of development options, and formulate ideas for guiding further change or growth in their neighborhood. In lesson five, Green Space, students investigate green infrastructure and native plant communities at the neighborhood, community, and regional scales and then explore the dual needs of accommodating population growth while protecting green space and native plant communities. In A Vision for the Future, the sixth lesson, student teams develop and present a vision for the future of an area in their community. Lesson seven, Far-Reaching Decisions, asks students to develop graphic organizers and creative presentations to illustrate how individual decisions can impact the local environment, as well as distant communities. They also measure their own ecological footprint. In the final lesson, The Ogallala Aquifer, students investigate a regional issue as they adopt the roles of shareholders and debate solutions to the depletion of North America's largest aquifer.

\section{Purpose}

The Places We Live curriculum was written to maximize the benefits demonstrated by the aforementioned research, and was designed to meet several objectives. First, completion of the les- 
sons was expected to provide students with the skills and knowledge required to be active participants in shaping their communities. Second, by completing the lessons it was expected that students would be more connected to the places they live (or the connections would be highlighted) so they will care about and influence the decisions being made about those places. Third, the designers of the Places We Live curriculum expected the curriculum would make students aware of environmental, social, and economic issues connected with community growth and change. Finally, it was hypothesized that completion of the lessons would demonstrate to students that their choices impact the environment and the quality of life in communities near and far.

The Places We Live curriculum was designed to adequately cover each of these objectives; however a formal research study to confirm the extent to which they are addressed by the curriculum has not been conducted. Therefore, we designed a national study of the curriculum to determine the extent to which the curriculum resulted in improved student attitudes and content knowledge about the places they live.

\section{Exploring Environmental Issues: Places We Live}

Our research questions are:

- Does exposure to the Places We Live curriculum result in a change in environmental attitudes with respect to the students' community?

- Does exposure to the Places We Live curriculum result in greater researcher-assessed content knowledge with respect to the issues covered in the curriculum, compared to other similar curricula?

- Does exposure to the Places We Live curriculum result in greater self-assessed content knowledge with respect to the issues covered in the curriculum, compared to other similar curricula?

\section{Methods}

This quasi-experimental research design seeks to determine the extent to which the Places We Live curriculum facilitates a change in students' self-assessed content knowledge, researcher-assessed content knowledge, and attitudes toward the places they live. Since the students were already assigned to a class in their schools, and it was not feasible to randomly assign students to a different class, an experimental research design was not possible. Thus, a quasi-experimental research design was implemented, wherein teachers were selected to participate in the study with two of the classes they taught during the 20072008 school year.

\section{Sampling}

Teachers that have had experience with the Places We Live curriculum were invited to participate in the study. Teachers were also recruited at national science education conferences. We sent invitations to participate to 20 teachers. All teachers agreed to participate but only 13 (65\% response rate) completed all of the study requirements, including pre- and post- test data collection. The end result was a sample size of 462 students, representing seven states. The minimum sample size needed at a $5 \%$ margin of error and a $95 \%$ confidence level is 377 (Hamburg, 1985). In comparison, Covitt et. al (2005), which we used as a model, obtained a similar sample size (532 students) for their evaluation of the Focus on Risk module.

Each teacher volunteered to participate in the study with two classes they teach. One of the classes was randomly assigned to the control group and the other class was assigned to the treatment group prior to initiating the study. To mitigate the results of teachers selecting their higher performing classes to complete the Places We Live curriculum, we decided that the study would be strengthened if classes were randomly assigned to the treatment group. Ten of the twenty teachers were randomly selected to teach 3-lessons from the Places We Live curriculum and use their other class as the control group, however only five of the teachers had complete data sets that were included in the study. Ten of the twenty teachers were randomly selected to teach 6 of the lessons from the Places We Live curriculum, with their other classes serving as the control group. Only eight of the ten teachers provided complete data sets that were included in the study. In sum, there were three groups of students: (1) the control group, (2) the 3-lesson treatment group and (3) the 6-lesson treatment group. Students in the control group were exposed to similar material, but by the traditional textbook or classroom materials, rather than by the Places We Live curriculum. The number of students in each group is shown in Table 1.

\section{Instruments}

The data collection for this study was collected utilizing survey methodology. Pre-test and post-test questionnaires were given to students in the control and treatment groups. In addition, the teachers completed a data log for each lesson they taught the treatment group and provided information about both the control and treatment groups.

The pre-test questionnaires consisted of 50 questions. Three questions measured basic demographic information: participation in the curriculum, gender, and grade level. The remaining questions measured self-assessed content knowledge, researcher-assessed content knowledge and students' attitudes toward the places they live (See the Appendix for sample questions from each section). The following sections provide a description of each subsection of the questionnaire.

\section{Self-Assessed Knowledge}

The twelve questions designed to measure self-assessed knowledge are stylistically similar in that each is a Likert-type question with seven answer choices. The answer choices were scored along a continuum from Strongly Agree (7) to Strongly Disagree (1), and I Don't Know was coded as zero (0). The total score for this section ranges from 84 to 0 , with 84 being the highest score demonstrating the greatest self-assessed knowledge of the environmental issues affecting the Places We Live.

\section{Content Knowledge}


Table 1. Teacher Demographics and Student Participation.

\begin{tabular}{|c|c|c|c|c|c|c|c|c|}
\hline Teacher & $\begin{array}{l}\text { Assigned } \\
\text { Group }\end{array}$ & State & Course & $\begin{array}{l}\text { Years } \\
\text { Teaching }\end{array}$ & $\begin{array}{l}\text { Highest } \\
\text { Degree }\end{array}$ & $\begin{array}{l}\text { Control } \\
\text { Participants } \\
(n=200)\end{array}$ & $\begin{array}{c}\text { Experimental } \\
\text { Participants } \\
(n=264)\end{array}$ & $\begin{array}{c}\text { Total } \\
\text { Participants } \\
(n=464)\end{array}$ \\
\hline 1 & 3 lesson & $A Z$ & World History & 9 & Master's & 22 & 41 & 63 \\
\hline 2 & 3 lesson & AR & Env. Science & 23 & Master's & 12 & 19 & 31 \\
\hline 3 & 3 lesson & $\mathrm{FL}$ & Biology & 24 & Master's & 12 & 10 & 22 \\
\hline 4 & 3 lesson & $\mathrm{FL}$ & Agriculture & 22 & Master's & 9 & 13 & 22 \\
\hline 5 & 3 lesson & $\mathrm{CO}$ & Env. Biology & 7 & Bachelor's & 9 & 10 & 19 \\
\hline 6 & 6 lesson & $\mathrm{FL}$ & Env. Science & 10 & Master's & 10 & 12 & 22 \\
\hline 7 & 6 lesson & $\mathrm{GA}$ & Literature & 2 & Specialist & 9 & 7 & 16 \\
\hline 8 & 6 lesson & $A R$ & Work-life skills & 23 & Master's & 19 & 36 & 55 \\
\hline 9 & 6 lesson & MD & Env. Science & 7 & Master's & 40 & 46 & 86 \\
\hline 10 & 6 lesson & $\mathrm{CO}$ & Geography & 7 & Master's & 14 & 20 & 34 \\
\hline 11 & 6 lesson & $\mathrm{CO}$ & Science Adventures & 518 & Bachelor's & 9 & 20 & 29 \\
\hline 12 & 6 lesson & $\mathrm{FL}$ & Science \& Reading & 2 & Master's & 16 & 9 & 25 \\
\hline 13 & 6 lesson & TX & AP Env. Science & 34 & Master's & 19 & 21 & 40 \\
\hline
\end{tabular}

The twenty-two researcher-assessed content knowledge questions each have favorable answers that indicate a superior level of understanding about the environmental issues affecting the places we live. Whereas the previous section measured how well students think they understand the environmental issues affecting the places they live, this section actually measures how well they do understand the environmental issues affecting the places they live. This section is scored as a multiple choice content knowledge assessment with distracters being viable options, but do not demonstrate the degree of understanding the most favorable answer choice represents. Thus, of the five possible answers, one is correct and three are incorrect. The incorrect answers were coded as zero (0) and the correct answer was coded as one (1). The response "I Don't Know" was coded as zero. The total score for the content knowledge section ranges from twenty-two (22) indicating superior knowledge to zero (0) indicating very little content knowledge. In addition to the total score, the mean and standard deviation for each question was determined.

\section{Attitudes}

Twelve questions were designed to measure students' attitude toward the places they live. The answer choices were scored along a continuum from Strongly Agree (7) to Strongly Disagree (1), and I Don't Know was coded as zero (0). The total score for this section ranges from 84 to 0 , with 84 being the highest score demonstrating the greatest self-assessed knowledge of the environmental issues affecting the Places We Live. Along with the total score the mean and standard deviation for each question was calculated.

\section{Instrument Reliability and Validity}

The researcher-developed instrument used in this study to measure students' self-assessed knowledge, content knowledge and attitudes has not been used in prior research. To that end, the reliability and validity of the instrument were determined prior to the study. A pilot study was conducted with 86 students who were not involved in the current research study.

\section{Reliability}

The reliability of an instrument is a measure of the amount of measurement error present in the scores yielded, where measurement error is the difference between an individual's true score on a test and the scores that are actually obtained on it over a variety of conditions (Gall, Gall \& Borg, 2003). To determine internal consistency of the self-assessed knowledge and attitude sections of the instrument a split-half correlation coefficient was determined. Chronbach's coefficient alpha was determined for each section of the instrument because it can be used when items are not scored dichotomously (Gall, Gall \& Borg, 2003). Since the self-assessed knowledge section and the attitude section utilize Likert-type responses that are weighted, the Chronbach's alpha measure is ideal for these sections. For the self-assessed content knowledge section Chronbach's alpha was found to be .80 and for the attitude section Chronbach's alpha was .73.

The content knowledge section of the instrument does contain correct and incorrect responses. To determine the test's internal consistency the method of rational equivalence was utilized. The Spearman-Brown prophecy formula was calculated for the content knowledge questions to determine reliability due to the short length of the knowledge section. The Spearman-Brown coefficient was found to be .75 .

\section{Validity}

To determine the validity of the instrument a panel of environmental educators, environmental consultants, city planners and teachers of grades 7-12 were given the instrument and the Places We Live curriculum. Each expert compared each of the 
self-assessed knowledge, content knowledge and attitude questions of the instrument to the Places We Live curriculum. With feedback from the experts, the instrument was revised and agreed to be valid based on expert analysis.

\section{Data Analysis}

Data collected from the control groups and both treatment groups (3-lesson treatment group and 6-lesson treatment group) was entered into SPSS. Both pre-test and post-test data was entered into SPSS and coded based on the control or treatment group each student was assigned to by the researchers. Analysis consisted of several steps. First, descriptive statistics were computed for each question from the pre-test and post-test. Second, an ANCOVA was performed to determine if the change in treatment scores was significantly different than the change in the control scores, with the covariate being the pre-test scores. Third, the pre-test scores were compared to the post-test scores for each group and for each of the 3 sections of the instrument to determine the extent to which the scores changed. The following sections describe each step in greater detail.

\section{Descriptive Statistics}

Each question from each of the 3 sections was coded as described above. The mean score was computed for each question. A total score for each section was then computed for each of the three groups: control group, the 3-lesson treatment group, and the 6-lesson treatment group. In addition to the mean score, the standard deviation was also computed.

\section{Effect of Treatment}

To determine the effect of the treatment (both 3-lesson and 6-lesson treatment groups) an analysis of covariance (ANCOVA) was conducted. The preferred statistical method is to compare the post-test mean of the experimental group with the post-test mean of the control group with the pre-test scores as the covariate (Gall, Gall \& Borg, 2003). By doing so, differences in the initial pre-test scores between the control group and the treatment group can be adjusted. Based upon the results of the ANCOVA, specific t-tests were conducted.

Pre-test-post-test gains.

In an attempt to determine pre-test-post-test gains within each group a t-test was computed for the control group and each treatment group. While these values do not speak to the significance of the treatment, they do provide an indication of the gain present within each group. This analysis enables us to speculate on the expected gain for those teachers who may choose to implement the curriculum in its entirety or to implement some lessons from the curriculum.

\section{Results}

\section{Pre- and Post-test Comparisons within Groups}

The mean for each of the three sections of the instrument were calculated and a t-test was conducted to ascertain if there was a statistically significant gain between the pre- and posttest applications (Table 2). The results indicate several significant gains $(p<.05)$. Both the 3 and 6 -lesson treatment groups showed significant gains on the student assessed content knowledge section ( $p=.00$ in both cases). Only the 6-lesson treatment group showed a significant increase in mean score on the researcher-assessed content knowledge section $(p=.04)$ and the attitude section $(p=.00)$ of the instrument. On all three sections the general trend was an increase in gains from pre-test to posttest with increased exposure to lessons. For example, the measurement of attitude indicates a slight decrease between pretest and post-test scores among the control group (-.10), a slight increase in scores among the 3-lesson treatment group (+1.74) and significant increase in scores among the 6-lesson treatment group (+7.46).

\section{Pre-test and Post-test Comparisons Across Groups}

\section{Analysis of Covariance Results}

An analysis of covariance (ANCOVA) was conducted wherein the mean scores of the control group, 3-lesson treatment group and 6-lesson treatment group were analyzed (Table 3). The pre-test scores were used as a covariate to provide an adjusted mean post-test score to account for differences in the initial abilities of the students as shown by the variance in pre-test scores. The results indicated significant differences across the three groups (control, 3-lesson treatment and 6-lesson treatment) on all three measures. There was a significant difference $(F=30.79$, $\mathrm{p}<.05$ ) between the three groups with respect to student assessed content knowledge. With respect to researcher-assessed content knowledge there was also a significant difference $(F=13.54, p<.05)$ among the three groups. Finally, a significant difference $(F=23.87, p<.05)$ was established among the three groups on the attitude measurement. The results of the ANCOVA were promising but they do not indicate between which groups there were significant differences. Thus, independent samples t-tests were conducted on the post-test mean scores.

\section{Independent Samples t-test Results}

With the results of the ANCOVA to guide us, we further explored the interaction between the treatment and control groups by computing independent samples t-tests. The t-tests permitted the comparison of the treatment groups to the control groups directly for each of the 3 measures. In the first series of tests we explored the difference between the 3-lesson treatment group and the control group (Table 4).

We hypothesized that there would higher scores among the 3-lesson group compared to the control group. While there was an increase among each of the three measures, only the researcher-assessed content knowledge measure yielded a significant difference $(p=.00)$ between the mean scores of the control group compared to the mean scores of the 3-lesson treatment group. The a priori established significance was set at .05 . For that reason, the students assessed content knowledge increase 
Table 2. Comparison of pre- and posttest mean class scores of dependent variables for 3 lesson experimental group $(n=93), 6$ lesson experimental group $(n=171)$ and control group $(n=200)$ participants.

\begin{tabular}{cllllll} 
& & \multicolumn{2}{c}{$M$} & & \multicolumn{2}{c}{$t$ Test } \\
\cline { 7 - 7 } \cline { 6 - 7 } Dependent variable & Group & Pretest & Posttest & & value & $p$ \\
\hline Student assessed & Control & 32.03 & 34.70 & & -1.67 & .10 \\
content knowledge & 3 lesson & 27.96 & 38.60 & -4.19 & .00 \\
Researcher assessed & 6 lesson & 35.66 & 47.21 & -7.03 & .00 \\
content knowledge & Control & 9.20 & 9.14 & .19 & .85 \\
& 3 lesson & 10.75 & 12.43 & -1.09 & .28 \\
Attitude & 6 lesson & 9.85 & 10.68 & -2.08 & .04 \\
& Control & 41.50 & 41.40 & .05 & .96 \\
& 3 lesson & 41.28 & 43.02 & .56 & .58 \\
& 6 lesson & 42.82 & 50.28 & -4.47 & .00
\end{tabular}

Table 3. Analysis of covariance for adjusted posttest mean scores on test measures between 6 lesson experimental group $(m=171), 3$ lesson experimental group $(n=93)$ and control group $(m=200)$.

\begin{tabular}{|c|c|c|c|c|}
\hline Measure & $\begin{array}{c}6 \text { lesson } \\
\text { experimental } \\
\text { group }\end{array}$ & $\begin{array}{l}3 \text { lesson } \\
\text { experimental } \\
\text { group }\end{array}$ & $\begin{array}{r}\text { control } \\
\text { group }\end{array}$ & $F$ \\
\hline \multicolumn{5}{|c|}{ Student assessed content knowledge } \\
\hline Pre M & 35.66 & 27.96 & 32.03 & \\
\hline Post M & 47.21 & 38.60 & 34.07 & \\
\hline Adj M & 46.54 & 40.57 & 34.96 & $30.79 *$ \\
\hline \multicolumn{5}{|c|}{ Researcher assessed content knowledge } \\
\hline Pre $M$ & 9.85 & 10.75 & 9.20 & \\
\hline Post M & 10.68 & 12.43 & 9.14 & \\
\hline Adj $M$ & 10.66 & 13.02 & 9.20 & $13.54^{*}$ \\
\hline \multicolumn{5}{|l|}{ Attitude } \\
\hline Pre M & 42.82 & 41.28 & 41.50 & \\
\hline Post M & 50.28 & 43.02 & 41.40 & \\
\hline Adj $M$ & 49.97 & 43.42 & 42.72 & $23.87^{*}$ \\
\hline
\end{tabular}

Table 4. Independent samples t-test comparison of posttest mean scores on test measures between 3 lesson experimental group $(n=93)$ and control group $(n=200)$.

\begin{tabular}{lccc} 
Measure & mean difference & value & $p$ \\
\hline $\begin{array}{l}\text { Student assessed } \\
\quad \text { content knowledge }\end{array}$ & 3.90 & -1.64 & .10 \\
$\begin{array}{l}\text { Researcher assessed } \\
\text { content knowledge }\end{array}$ & 3.29 & -5.37 & .00 \\
Attitude & 1.61 & -.64 & .52
\end{tabular}

cannot be considered significant even though we can be $90 \%$ certain that the increased scores among the 3-lesson treatment group were a result of exposure to the Places We Live curriculum.

Again, we hypothesized that the greatest increases on all three measures should take place between the 6-lesson treatment group and the control group. The results of the independent samples t-tests indicated significant differences between the 6-lesson treatment group and control group on all three measures. As indicated in Table 5, the mean differences be- tween the groups were significant at the $p=.00$ level for the student assessed content knowledge, researcher-assessed content knowledge, and attitude measures.

At the outset of this quasi-experimental research, we hypothesized that greater exposure to the Places We Live curriculum should result in greater gains on the three measures. The adjusted means shown in Table 3 indicate a general trend of increased scores with the lowest scores among the control group and the highest scores among the 6-lesson treatment group. The 
Table 5. Independent samples t-test comparison of posttest mean scores on test measures between 6 lesson experimental group $(n=171)$ and control group $(n=200)$.

$\begin{array}{lccc}\text { Measure } & \text { mean difference } & \text { value } & p \\ \begin{array}{l}\text { Student assessed } \\ \quad \text { content knowledge }\end{array} & 12.51 & -6.88 & \\ \text { Researcher assessed } & & & .00 \\ \quad \text { content knowledge } & 1.54 & -3.98 & .00 \\ \text { Attitude } & 8.88 & -4.72 & .00\end{array}$

exception to this trend is the researcher-assessed content knowledge scores were actually highest among the 3-lesson treatment group. This may be, in part, due to the lower number of participants in the 3-lesson treatment group, which may have been high achieving students. This would not influence the other measures which are self-reports of their content knowledge and attitude toward the place they live.

\section{Discussion}

One difference between this evaluative study and other evaluative studies conducted on Project Learning Tree curricula is that, in the present study, teacher participants were assigned researcher-specified lessons to cover with their students. Previous studies had teachers choose which lessons to present (Covitt et. al. 2005). We feel that our results are more powerful given that each participant within a treatment group administered the same portion of the curriculum.

The current study sought to resolve three questions:

- Does the Places We Live curriculum improve students' attitudes toward the environment and their place in it?

- Does the Places We Live curriculum increase students' content knowledge about environmental issues and their community?

- Does the Places We Live Curriculum improve students' perceptions of the amount of knowledge they maintain with respect to the environmental issues and attributes within the places they live?

The results suggest the answer to each of these questions is yes, but also provide more detailed insight into the effects the curriculum had on the students.

\section{Student Assessed Content Knowledge}

The pre-test-post-test comparison of student assessed content knowledge did not change significantly among the control group. However, there was a significant gain among the 3-lesson treatment group and the 6-lesson treatment group, although the gain was slightly greater among the 6-lesson treatment group suggesting that exposure to the curriculum increased students' self-reported content knowledge. Thus, participation in the curriculum provided students with a sense that they could contribute to, and help solve environmental issues within their communities. Additionally, a comparison of post-test scores indicates that the only significant gains produced were between the control and 6-lesson treatment groups, suggesting that the curriculum is most beneficial when not parceled out into separate lessons. This is an important finding for teachers and teacher educators, given the range and depth of content that teachers are required to cover over the course of an academic year. This finding clearly indicates the importance of utilizing curricular materials in their entirety for maximum gains. Moreover, a comparison of the 3-lesson group to the control group indicates that students only receiving 3 -lessons did not feel they could solve environmental issues in their community any more than did students in the control group.

\section{Researcher-Assessed Content Knowledge}

The content knowledge assessed by the researchers indicates a similar pattern to the students' self-reported content knowledge. As the amount of exposure to the Places We Live curriculum increased, so too, did the researcher-assessed content knowledge. A comparison of pre-test to post-test scores indicated that the only significant gains were among the 6-lesson treatment group. Thus, the lessons the control group were exposed to, i.e. the teacher's normal curricular materials, did not produce an increase in content knowledge regarding the environmental issues affecting the places the students live. A comparison of the post-test scores did indicate a significant increase among both the three and 6-lesson treatment groups. This finding indicates that much of the tested information would not normally be acquired by the students in the classes partaking in this study. These results also indicate that teaching portions of a curriculum can still have beneficial effects for students, although the more of the curriculum covered, the more benefits that were reaped. While we had hoped to see gains among the 3-lesson treatment group in self-assessed knowledge and attitude, we are quite pleased to see that even exposure to a short segment of the module did produce significant gains in researcher-assessed content knowledge. However, if educators seek to teach students who can make informed decisions about the environmental issues affecting their community, the entire curriculum is likely to produce better results than selecting individual lessons from the curriculum. Teaching only 3-lessons did significantly increase researcher-assessed content knowledge though students lacked the confidence to indicate that they thought they could solve environmental issues. Among the 6-lesson group, not only did the students have a better knowledge base, but they also devel- 
oped the confidence to feel that they could contribute to solving environmental issues in their communities.

\section{Attitudes}

There are few studies that have been able to demonstrate a significant change in environmental attitude or change in behavior toward the environment (Bamburg \& Moser, 2007; Barr, 2007; Heimlich \& Ardoin, 2008). Such influences have been difficult to demonstrate. Although it is not possible for us to longitudinally track changes in environmental attitude among the students involved in this study or to determine whether their exposure to the curriculum will bring about a change in their behavior toward the environment, the results shown here are promising, and reiterate the concept that the more exposure students have to environmental education and environmental issues, the more stewardship they will feel towards the environment.

Whereas the control group made almost no gains during the time of the study, the 6-lesson treatment group made significant gains in their attitudes about the environment and their place in it. Students were clearly able to identify the salient aspects of their environment and the challenges to maintaining a community given the external pressures often placed on communities as they grow and evolve. The students who completed 6-lessons of the curriculum had much more positive attitudes regarding their ability to identify and help solve environmental issues in their communities. There was not a significant difference between the control and 3-lesson post-test scores, but there was a significant difference between the control group and the 6-lesson treatment group with respect to their attitudes about their communities and their abilities to solve community related environmental issues. Clearly the completion of all 6-lessons produced the most significant increase in the students' attitudes toward environmental issues, resulting in a group of students who are more confident in their ability to help solve complex socioscientific issues.

\section{References}

Athman J and M Monroe (2004) The effects of environment-based educa $\neg$ tion on students' achievement motivation. Journal of Interpretation Research 9 (1): 9-25.

Bamburg S and G Moser (2007) From intentions to actions: A theory of planned behavior. In J. Kuhl \& J Beckmann (Eds), Action control: From cognition to behavior. (pp. 11-39). Berlin, Germany: Springer-Verlag.

Barr S (2007) Factors influencing environmental attitudes and behaviors. Environment \& Behavior 39: 435-473.

Bartosh $\bigcirc$ (2003). Environmen ᄀtal education: Improving student achievement. Master Thesis, Evergreen State College, Olympia, WA.

Bodzin A (2008) Integrating instructional technologies in a local watershed investigation with urban elementary learners. Journal of Environmental Education 39 (2): 47-57.

Covitt BA, C Gomez-Schmidt, and M Zint (2005) An evaluation of the risk education module: Exploring Environmental Issues-Focus on Risk. Journal of Environmental Education 36 (2): 3-13.

Dewey J (1915) The school and society (Rev. ed.). Chicago, IL: The University of Chicago Press.

Duffin M, A Powers, G Tremblay, and PEER Associates (2004) Placebased education evaluation collabora $\neg$ tive: Report on cross-program research and other program evaluation activities, 2003-
2004. (http://www.peecworks.org/PEEC/PEEC_Reports).

Duffin M, M Murphy, and B Johnson (2008) Quantifying a relationship between place-based learning and environmental quality: Final report. Woddstock, VT: NPS Conservation Study Institute in cooperation with the Environmental Protection Agency and Shelburne Farms.

Ernst JA, and M Monroe (2004) The effect of environment-based education on students'critical thinking skills and disposition toward critical thinking. Environmental Education Research 10: 507-522.

Falco EH (2004) Environment-based education: Improving attitudes and academics for adolescents. Evaluation report for South Carolina Depart $\neg$ ment of Education.

Frazier R, P Hegger, T Grotzinger, and S Sarkar (2008) “They're Buggin Me"- real data, real sixth graders, and real insects in the school yard. Boston, MA: Presentation at the Annual Conference of the National Science Teachers Association.

Gall M, JP Gall, and W Borg (2003) Educational Research: An introduction. Boston: Allyn and Bacon.

Gravett L, and MA Throckmorton (2007) Bridging the generation gap. The Career Press; New Jersey.

Hamburg M (1985) Basic Statistics: A Modern Approach. Harcourt Publishers.

Heimlich J and N Ardoin (2008) Understanding behavior to understand behavior change: a literature review. Environmental Education Research 14 (3): 215-237.

Lieberman GA and L Hoody (1998) Closing the achievement gap. San Diego, CA: State Education and Environment Roundtable.

Lippincott JK (2009) Net generation students and libraries, Retrieved November 30, 2009 from http://www.educause.edu.

Marcinkowski T and L Lozzi (1994) Project Learning Tree National Field Study Executive Summary. www.plt.org.

Martin SC (2003) The influence of outdoor schoolyard experiences on students' environmental knowledge, attitudes, behaviors, and comfort levels. Journal of Elementary Science Education 15 (2): 51-63.

National Environmental Education Training Foundation (NEETF) (2000). Envi ᄀronment-based education: Creating High Performance Schools and Students. Washington, DC: Author.

Orr DW (1994) Earth in mind: On education, environment, and the human prospect. Washington, DC: Island Press.

Project Learning Tree (1976) PreK-8 environmental education activity guide. Washington, DC: American Forest Foundation.

Sarkar S, and R Frazier (2008) Place-based investigations and authentic inquiry. The Science Teacher 75 (2): 29-33.

Smith GA, and DR Williams (Eds.) (1999) Ecological education in action: On weaving education, culture, and the environment. Albany, NY: State University of New York Press.

Sobel D (2004) Place-based education: Connecting classrooms and communities. Great Barrington, MA: The Orion Society.

State Education and Environment Roundtable (SEER) (2000) California student assessment project: The effects of environment-based education on student achievement. San Diego: Author.

Theobald P, and J Curtiss (2000) Communities as curricula. Forum for Applied Research and Public Policy 15 (1): 106-111.

Traina F, and S Darley-Hill (Eds.) (1995) Perspectives in bioregional education. Troy, OH: North American Association for Environmental Education.

Thomashow M (1995) Ecological identity: Becoming a reflective environmentalist. Cambridge, MA: The MIT Press.

UNESCO-UNEP (1976) The Belgrade Charter. Connect: UNESCO-UNEP Environmental Education Newsletter 1 (1): 1-2.

Woodhouse J, and C Knapp (2000) Place-Based curriculum and instruction: outdoor and environmental education approaches. ERIC Clearinghouse on Rural Education and Small Schools: Charleston, WV. 


\section{Appendix}

\section{Examples of Self-Assessed Content Knowledge Questions}

I can identify features that add and detract from a community's appearance.

I know how maps are made.

I know how government officials make land use decisions.

\section{Examples of Researcher-Assessed Content Knowledge Questions}

As communities grow and change over time they are faced with the loss of natural green spaces. These changes often occur as communities expand and economic opportunities arise. The green space may be enjoyed for recreational opportunities, however, buildings placed in that location can add to the economy of the community. Therefore, many times individuals disagree with one another with respect to the appearance of a community. Some individuals may focus on the economic growth of the community while other individuals may focus on the environmental impact growth may have on the community. Some individuals may have other concerns about the growth of the community.

The example above illustrates what are known as
A. Land use issues
B. Infrastructure problems
C. Zoning regulations
D. Cost/benefit ratios
E. I don't know

As discussed above, individuals, or groups of individuals, have different ideas about the way a community should appear. Individuals who have opinions about the way a community should look are called
A. Business partners
B. Citizens
C. Residents
D. Stakeholders
E. I don't know

\section{Examples of Students' Attitudes towards the Places They Live Questions}

The growth and expansion of a community has both positive and negative qualities.

It is my personal responsibility to help ensure that my community maintains its positive qualities as the community expands and grows. Experts make better decisions about a community's vision for the future than laypeople. 